\title{
Editorial
}

\section{Sobre tempos pandemônicos, e para além deles}

\author{
Eliana Santos Junqueira Creado (UFES) \\ Paulo Magalhães Araújo (UFES) \\ Nara Lima Mascarenhas Barbosa (UFES)
}

$\mathrm{N}$ esse primeiro volume de 2020, apresentamos novamente textos de temas livres submetidos em regime de fluxo contínuo. Trata-se de um grande privilégio para nós, pois, novamente, autoras e autores aqui contemplados apresentaram seus artigos ao Cadecs voluntaria e livremente, em regime de fluxo contínuo, o que denota a consolidação do periódico, que nasceu ligado ao Programa de Pós-Graduação em Ciências Sociais da Universidade Federal do Espírito Santo (PGCS-UFES), e ao qual ainda se vincula.

Observamos que o referido programa também tem se consolidado, sendo o único programa de pós-graduação em Ciências Sociais do Espírito Santo ligado a uma universidade pública e com formação em nível de mestrado e doutorado, desde o final de 2018, após seu mestrado alçar a nota 4 em avaliação da CAPES.

Assim, o PGCS-UFES, bem como o Cadecs, tem o desafio de se fortalecer em um contexto muito difícil para o nosso país como um todo e, em especial, para suas universidades públicas e, sobretudo, suas pós-graduações, por conta dos muitos ataques e mudanças que ocorrem com maior força na atual conformação política em âmbito federal. Importante notar que a conferência que fecha o volume, ministrada na aula inaugural do Doutorado nesse PPG, pelo prof. Dr. Marcelo Rosa, do Departamento de Sociologia da UnB, em março de 2019, teve algumas palavras nesse sentido.

São muitas as crises e dificuldades vivenciadas; algumas delas pré-existentes, mas potencializadas com a pandemia da Covid-19, que atingiu o Brasil no começo de 2020, e que deve persistir, em pelo menos por parte de 2021, e cujos efeitos, infelizmente, deverão se prolongar a médio prazo.

No âmbito das universidades, e também em outros níveis e tipos de instituições de ensino, a pandemia exigiu toda uma reformulação nas atividades exercidas, por conta das exigências do isolamento social. Docentes, discentes, técnicos e demais colaboradores da UFES (e não apenas) foram e continuarão a ser afetados, mas esperamos que possamos retomar ao menos parte de nossas atividades prévias presencialmente, tão logo as condições sanitárias permitam, e com algumas de nossas muitas cicatrizes curadas. 
Por enquanto, é importante registar que, no fechamento deste número, tivemos mais de um milhão e trezentas mil mortes pelo mundo, quase cento e setenta mil no Brasil e mais de quatro mil no Espírito Santo. ${ }^{1}$ Neste momento, o estado em que vivemos, voltou a proibir o funcionamento das escolas a partir de 23 de outubro de 2020, após um curto período de funcionamento, por conta do aumento de infectados e de ocupações nas unidades de saúde.

Como se não bastasse tudo isso, nosso país como um todo, com problemas infra estruturais crônicos, não apenas na saúde, precisa lidar também com controvérsias políticas sobre a procura da vacina, dada uma conjunção de lideranças e apoiadores embasados na política de espantalho e nos mais diversos negacionismos, para os quais a vida humana, em suas diversas dimensões, importa pouco, sobretudo aquelas que não se aliam a projetos caracterizados sobretudo pela falta de propostas e pelo ressentimento. Não é também uma surpresa que outras vidas, não humanas, também sejam consideradas tão desimportantes, como também o comprova o descaso acentuado com as questões ambientais e a defesa dos direitos humanos.

De nossa parte, aproveitamos para nos solidarizar com todas aquelas e todos aqueles que sofreram as mais variadas perdas nesses últimos tempos, perdas que podem ter-se acumulado com perdas anteriores, tenham sido elas perdas de entes que amam e ou de que cuidam, bem como perdas por conta da crise sócio-econômica-política geral. Solidarizamo-nos também com aquelas e aqueles que, por diversas razões, dentre as quais suas atividades laborais e a falta de apoios os mais variados, precisam arriscar suas vidas diariamente. Igualmente, preocupamo-nos com as/os idosas/os e as/os mais jovens, uns por conta do isolamento, outras/os por conta da falta de perspectiva.

Nesse sentido, importante notar também o primeiro texto do volume, que aborda a juventude, e pode ser utilizado para pensarmos os desdobramentos de toda essa confluência de acontecimentos e posicionamentos junto aos mais jovens. 0 primeiro texto, juntamente com outros do mesmo volume, permite-nos refletir também sobre tais efeitos junto às mais diversas minorias do país. Nesse sentido, registramos o recrudescimento da violência tanto no estado do Espírito Santo quanto no Brasil. Para se ter uma ideia, antes do encerramento do mês de novembro de 2020, o estado do Espírito Santo totaliza mais de mil assassinatos, enquanto ao longo de todo o ano de 2019, o número total fora de $978 .{ }^{2}$ Mencionamos o recente espancamento, seguido de morte por asfixia, de João Alberto Silveira Freitas, em supermercado Carrefour de Porto Alegre, Rio Grande do Sul, em um ato de brutalidade incontida, que ainda contou com o testemunho de muitas pessoas que não agiram em sua defesa. ${ }^{3}$

\footnotetext{
1 Portal Covid-19, do Google Notícias, consultado em 22.11.2020, link: https: //news.google.com/covid19/map?hl=pt-BR\&gl=BR\&ceid=BR\%3Apt-419 .

${ }^{2}$ Portal A Gazeta, acessado em 23.11.2020. MENDONÇA, MAÍ́RA. Passa de mil o número de assassinatos registrados no ES em 2020. Disponível em: https://www.agazeta.com.br/es/policia/passa-de-mil-onumero-de-assassinatos-registrados-no-es-em-2020-1120 .

${ }^{3}$ Como o apontado em uma notícia sobre o assunto:
}

Caderno Eletrônico de Ciências Sociais, Vitória, v. 8, n. 1, pp. 1-8. 
O presente número representa, portanto, nosso compromisso em tentar manter a qualidade do Cadecs em águas muito turbulentas, com muito empenho pessoal inclusive, dado que nossas atividades, como na maioria dos periódicos acadêmicos brasileiros, são realizadas em caráter de voluntariado.

Passamos à apresentação das colaborações textuais do volume, e de suas autoras e seus autores, ligados a instituições do Sudeste, Nordeste e Centro Oeste. Muito agradecemos pelas preciosas colaborações!

O primeiro artigo é "Sociabilidades juvenis: notas etnográficas na periferia de Florianópolis-SC". Seu autor é Valdeci Reis, doutor em educação pela Universidade do Estado de Santa Catarina (UFSC). $\mathrm{O}$ artigo liga-se justamente à pesquisa de doutoramento do mesmo, na qual realizou um estudo etnográfico sobre jovens do movimento hip-hop, em Florianópolis, Santa Catarina.

As batalhas, os ritmos $\mathrm{e}$ as poesias compartilhadas vão muito além de visões estereotipadas sobre o hip-hop e remontam também a uma ampla formação de si, que inclui a crítica e a atuação política. As convergências e os estranhamentos entre pesquisador e interlocutores em campo também aparecem no artigo, a partir de abordagem e escrita com inspirações etnográficas. A pesquisa e as reflexões trazidas apresentam interface com as Ciências Sociais, não apenas na escrita e nas técnicas de pesquisa, mas também na preocupação do mesmo e de seus interlocutores com a precarização das condições do Estado brasileiro, sobretudo no que diz respeito às parcas políticas públicas devotadas para a juventude; preocupação também dos interlocutores de pesquisa de Valdeci Reis.

0 autor procura categorizar o movimento como um dos novos movimentos socias, em especial as batalhas de rap, por suas articulações com outros movimentos, como o movimento estudantil e as associações de bairro - embora dissensos a respeito dos vínculos políticos sejam verificados junto a seus integrantes. Reis destaca a busca desses jovens por "uma sociedade mais inclusiva e respeitosa", o que não deve ser vinculado a interpretações conspiratórias. A parte final do texto com uma apresentação sobre a importância do acesso à Educação em trajetórias individuais de alguns desses jovens é muito cuidadosa e sensível, e merece o nosso destaque aqui, sobretudo no momento que vivemos.

"Em 2019, 3 de cada 4 vítimas de homicídio ou latrocínio no Brasil eram negras, segundo o Fórum Brasileiro de Segurança Pública. Dados do fórum e do Ipea mostram que os homicídios de pessoas negras no país aumentaram 11,5\% de 2008 a 2018, enquanto os de pessoas não negras caíram 12,9\%". Fonte: Folha de SP. CAMARGO, Cristina; SPERB, Paula. Homem negro morre após ser espancado por seguranças do Carrefour em Porto Alegre; veja cenas. Acesso em 23.11.2020. Disponível em: https://www1.folha.uol.com.br/cotidiano/2020/11/homem-negro-morre-apos-ser-espancado-porsegurancas-do-carrefour-em-porto-alegre.shtml 
O segundo artigo intitula-se "Crônicas urbanas, espaços de solidão e afetos desestabilizados no cinema latino-americano". Seu autor é Wendell Marcel Alves da Costa. Como no caso do primeiro artigo, trata-se de manuscrito ligado a pesquisa de doutoramento, aqui, em Sociologia e pelo Programa de Pós-Graduação em Sociologia da Universidade de São Paulo (USP). A pesquisa foi iniciada em oportunidade anterior em outro programa de outro estado: Rio Grande do Norte e em programa de mestrado em antropologia. 0 manuscrito traz análises fílmicas sobre a solidão em grandes cidades da América Latina, sobretudo a partir dos filmes Buenos Aires na Era do Amor Virtual (Gustavo Taretto, 2011) e O Homem das Multidões (Marcelo Gomes e Cao Guimarães, 2013), que se passam respectivamente em Buenos Aires, Argentina, e Belo Horizonte, Brasil.

As categorias de espaço e tempo foram crucias para o autor, bem como autoras/es da teoria da modernização e da pós-modernidade por ele utilizados. Muitas evocações, tanto de filmes quanto de cidades outras, emergem no artigo, que procura dialogar com preocupações sociológicas, antropológicas, filosóficas, mas também com o cinema e o urbanismo. O nó górdio que liga essas evocações fílmicas e bibliográficas foram os afetos desestabilizados, em especial a solidão, demonstrando muito bem que se cercar de pessoas e ter possibilidades virtuais de interação não garantem que não se esteja só.

Nesse sentido, o segundo artigo contrasta bem com as experiências pulsantes trazidas no artigo precedente, embora tenha também a urbe como ambiência. Ambos colocam então as diferentes espacialidades e temporalidades possíveis nas cidades, e para retomarmos algumas palavras de Alves da Costa: "Como produto mimético do mundo, a obra cinematográfica não se compromete com a realidade social, mas, ao projetar imagens da mesma, desenha contornos daquilo que se pode conceber como fenômenos sociais". Ou pelo menos, poderíamos emendar: determinados fenômenos sociais para determinadas pessoas ou determinados grupos.

Seguindo ainda pelos caminhos das cidades, temos o terceiro artigo, "Megatemplos evangélicos na experiência urbana”, de autoria de Rita Gonçalo, Doutoranda em Planejamento Urbano e Regional pela Universidade Federal do Rio de Janeiro (UFRJ). 0 manuscrito associa-se a pesquisa realizada entre 2017 e 2020. Como no primeiro artigo do volume, teve também inspiração etnográfica, combinando-a com pesquisa bibliográfica. A autora coloca o aumento da importância dos megatemplos no Brasil entre 1990 e 2000 e ressalta que tais edificações, na verdade, são provedoras dos mais diversos serviços sociais, visando ocupar muitas vezes funções deixadas esvaziadas pelo Estado, de modo que cada megatemplo:

"Refere-se, assim, a um espaço qualitativo e dinamizado, um elemento de marketing estratégico da religião, pois se configura não apenas como uma ocupação espacial, mas também como um equipamento urbano, cujo aspecto mais análogo ao capitalismo corresponde à oferta de diferentes modalidades de serviços - sociais, culturais, educacionais e de entretenimento - individuais e coletivos".

Caderno Eletrônico de Ciências Sociais, Vitória, v. 8, n. 1, pp. 1-8. 
O funcionamento dos megatemplos dá-se através das aglomerações, e atividades econômicas associadas. Tais edificações possuem também estética e ideologia próprias. 0 artigo focou, em maior detalhe, em dois dos primeiros megatemplos, surgidos no Brasil durante a década de 1990, sendo que os dois possuem diversas particularidades, o que contribui para a análise comparativa trazida. A saber: a Primeira Igreja Batista de Curitiba, Paraná, em Batel; e o Templo da Glória do Novo Israel, IURD em Del Castilho, no Rio de Janeiro. $O$ advento dos megatemplos brasileiros é colocado em diálogo com o das mega igrejas cristãs norte-americanas, surgidas bem antes, no começo do século XX. Assim, Gonçalo afirma que há todo um “modelo mental” dos megatemplos.

O quarto artigo é "Políticas Identitárias - um diálogo com as críticas de Francis Fukuyama e Mark Lilla", redigido por Jorge Henrique Oliveira de Souza Gomes. Trata-se de artigo de revisão bibliográfica associada a pesquisa de doutoramento em Ciência Política, realizada na Universidade Federal de Pernambuco. A revisão gira ao redor da polêmica discussão trazida pelos dois autores mencionados no título, que visaram ampla circulação e público para além do acadêmico, respectivamente Foreign Affairs e The New York Times: "Against Identity Politics", de Francis Fukuyama, e "The End of Identity Liberalism", de Mark Lilla. Esses textos foram escritos depois do resultado da eleição anterior para presidente nos EUA, em que Donald Trump saíra vitorioso, sendo que nas análises desses dois cientistas políticos, defensores do liberalismo, as pautas identitárias do Partido Democrata, mais voltadas para minorias, explicariam, ao menos em parte, a sua derrota.

0 artigo pondera os dois manifestos com literatura mais ampla e que reflete sobre a crise atual das democracias, apontando ainda a necessidade de se considerar as especificidades e os históricos dos vários países, e estabelece um diálogo específico com o caso brasileiro, trazido ao final do artigo.

No caso da análise a partir do texto de Francis Fukuyama, e outras de suas obras, Gomes, por exemplo, coloca-o como mais cauteloso do que Mark Lilla. Coloca que foram as próprias democracias liberais institucionalizadas que permitiram a eclosão dos movimentos identitários, que possuem sim sua razão de ser, e critica, dentre outros aspectos, a possibilidade de associação entre os movimentos de esquerda e os movimentos identitários e reativos de direita - aberta por Francis Fukuyama.

Se, por um lado, algumas críticas dos dois teóricos podem ser válidas, por outro, seus posicionamentos nos dois artigos, ao seguirem a linha do rechaço, podem acabar por recrudescer as polarizações. Para o autor, é mister reconhecer a existência de outras vertentes de liberalismo, como o negro, o feminista e o social-democrata, e não apenas o dominante, mobilizado por Fukuyama e Lilla.

O presente volume do Cadecs está sendo fechado após a divulgação do resultado do pleito de 2020, em que nova guinada se deu, com a vitória do Partido Democrata, com a não reeleição de Donald Trump nos EUA. Com certeza, novos desafios virão para essa democracia, para além de seus velhos enfrentamentos. Destarte, leitoras e leitores poderão contar com as muitas reflexões trazidas, tanto sobre o caso norte-americano quanto sobre o caso brasileiro.

Caderno Eletrônico de Ciências Sociais, Vitória, v. 8, n. 1, pp. 1-8. 
O quinto artigo é "Por que Lula usou o Mensalão como ferramenta de gestão da coalizão?", de Maristela Mendes de Sant'Ana. Maristela é Mestre em Ciência Política com ênfase em Poder Legislativo pelo Centro de Formação, Treinamento e Aperfeiçoamento da Câmara dos Deputados (CEFOR). O artigo é fruto da dissertação de mestrado da autora, onde a principal questão a ser respondida era: "Por que o governo Lula substituiu, ao menos em parte, as tradicionais ferramentas de gestão da coalizão pela remuneração de parlamentares e de partidos políticos - o que ficou conhecido como Mensalão?"

Para responder a essa pergunta, a autora, fundamentada pela lente analítica do institucionalismo histórico, bem como pela teoria da escolha racional, retoma a história do Partido dos Trabalhadores (PT) em seu artigo. Para tanto, se reporta à análise de documentos como o relatório final da Comissão Parlamentar Mista de Inquérito (CPMI) dos Correios - conhecida como CPMI do Mensalão -, documentos da AP 470. Também realizou entrevistas com figuras marcantes na trajetória do PT.

Mendes de Sant'Ana demonstra como princípios e características presentes na origem do partido fizeram com que ele traçasse mudanças para chegar ao poder - elegendo seu principal líder - e, posteriormente, para se manter no poder - através do uso do Mensalão como principal instrumento de gestão da coalização. Sobre isso, conclui que o PT: "Para conseguir governar, mas seguir hegemônico e manter a imagem construída em suas origens, incorporou o Mensalão à caixa de ferramentas de gestão da coalizão (presidential toolbox)". Certamente, a partir desse estudo de caso, tem-se bons elementos, em termos de análise e abordagem teórico-metodológica, para refletir e entender sobre uma importante fase da história política brasileira.

Por último, mas não menos importante, temos a Conferência do Prof. Dr. Marcelo C. Rosa (UnB), ministrada como aula inaugural do curso de doutorado em Ciências Sociais do PGCS-UFES, em março de 2019. Além de agradecermos ao próprio autor pela autorização na sua publicação, gostaríamos também de agradecer: ao prof. Dr. Sandro Silva, ligado ao PGCS-UFES, que naquela oportunidade gravou a conferência; ao Glendo da Silva Nascimento, aluno da graduação em Ciências Sociais, UFES, responsável pela transcrição da conferência; e à profa. Profa. Dra. Adélia Miglievich-Ribeiro, que tanto mediou a vinda do prof. Dr. Marcelo C. Rosa naquela oportunidade quanto fez a primeira revisão da conferência tornada texto. Outras e outros também muito colaboraram para a viabilização do evento, inclusive os discentes do programa que compareceram em peso, juntamente com colegas e discentes da graduação em Ciências Sociais, tanto na conferência quanto nas demais atividades realizadas durante aquela semana inaugural.

Caderno Eletrônico de Ciências Sociais, Vitória, v. 8, n. 1, pp. 1-8. 
Foto 1. Profa. Dra. Adélia Miglievich-Ribeiro, vinculada ao DCSo e ao PGCS-UFES, e prof. Dr. Marcelo Carvalho Rosa, Departamento de Sociologia e Programa de Pós-Graduação em Sociologia da UnB, aula inaugural do período 2019/1:

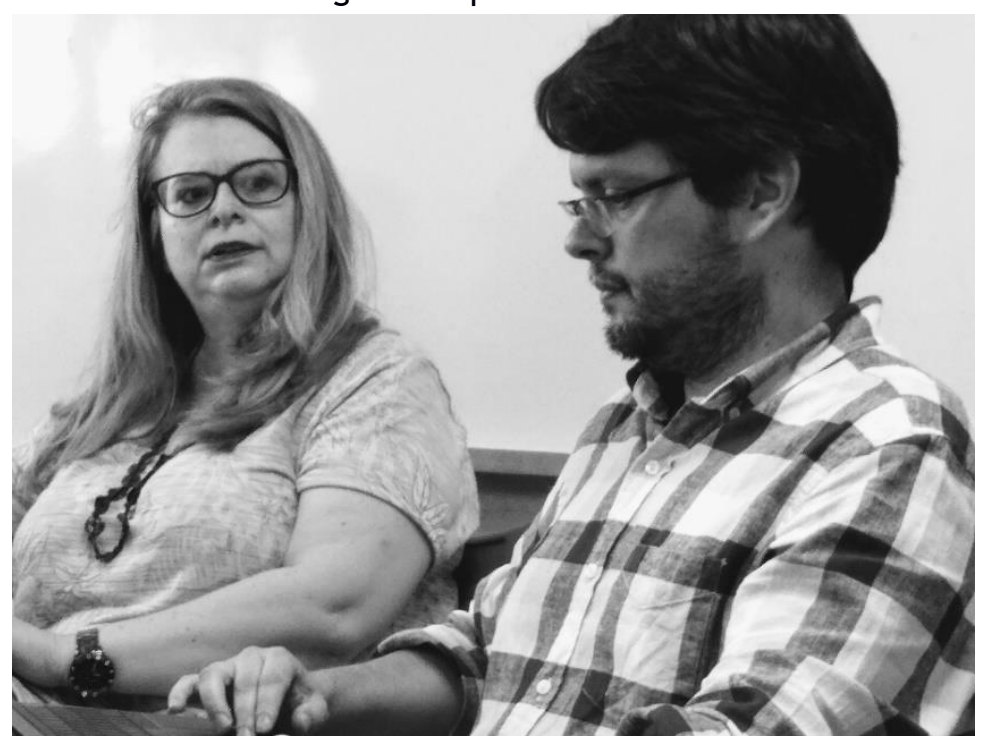

Fonte: Autoria de Eliana Creado.

Foto 2. Aula inaugural do período 2019/1:

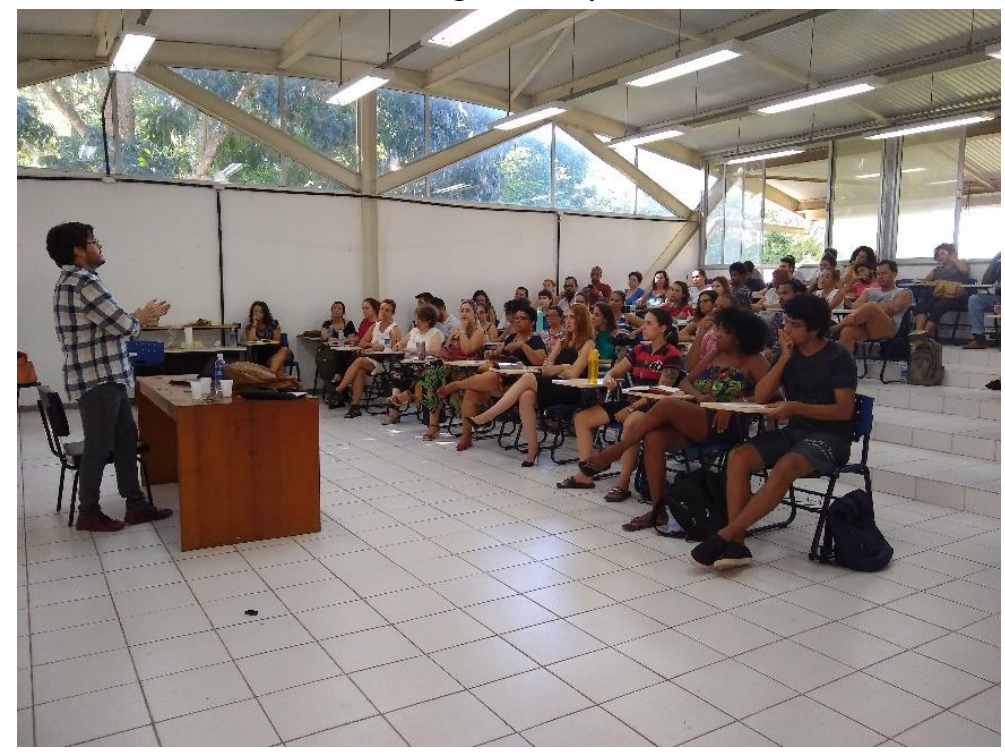

Fonte: Autoria de Eliana Creado.

A conferência "Sociologias Emergentes: uma agenda não-exemplar", a partir de uma perspectiva construída a partir da Sociologia, tece caminhos cheios de possibilidades para engajamentos outros entre teoria-e-empiria. A partir dela, e agora de sua versão textual, podemos seguir os entrelaçamentos da própria trajetória de seu autor, seus trabalhos e pesquisas, com a da própria disciplina e da instituição da qual faz parte.

Há a proposta de maior inclusão das "sociologias emergentes" em cursos de graduação e pós-graduação em Ciências Sociais, de modo a que ela represente o repensar dos próprios pilares canônicos da Sociologia e permita a inclusão de outros mundos em suas reflexões. Inclusive, isso permitirá rever as análises sobre o Brasil, que muitas vezes são filtradas 
por abordagens e teorias construídas a partir de outros pontos de referência, resultando em enquadramentos forçados ou desencaixados, obliteradores de existências. Quiçá, tomamos aqui a liberdade de pensar se podemos também refletir sobre própria colonização existente dentre das próprias Ciências Sociais em nosso país, em que a Sociologia acaba tendo mais prevalência. Daí também um dos desafios colocados a programas de pós-graduação interdisciplinares, dentre os quais o PGCS-UFES.

Outro ponto forte da conferência tornada palavras escritas é nos apresentar toda a riqueza e diversidade de autoras e autores, tão lindamente conjugados pelo conferencista. Acreditamos também que o formato em texto permitirá maior acesso às ideias ali contidas e sistematizadas, bem como às demais contribuições e reflexões trazidos por Rosa. 0 manuscrito é um maravilhoso passeio planetário e ontológico. Registramos que a conferência em si mesma também foi um momento muito especial. Novamente, nossos agradecimentos! Que possamos, em breve, ter mais dessas convivências presenciais!

Por fim, desejamos muita saúde a todas e a todos; agradecemos pelas colaborações envolvidas neste número, de autoras, autores, pareceristas, bem como de leitoras e leitores. Seguimos com a esperança de tempos melhores, não apenas relegados ao futuro, mas também que se façam presente(s)! Boas relações de (auto)cuidado. Até o próximo número.

Caderno Eletrônico de Ciências Sociais, Vitória, v. 8, n. 1, pp. 1-8. 